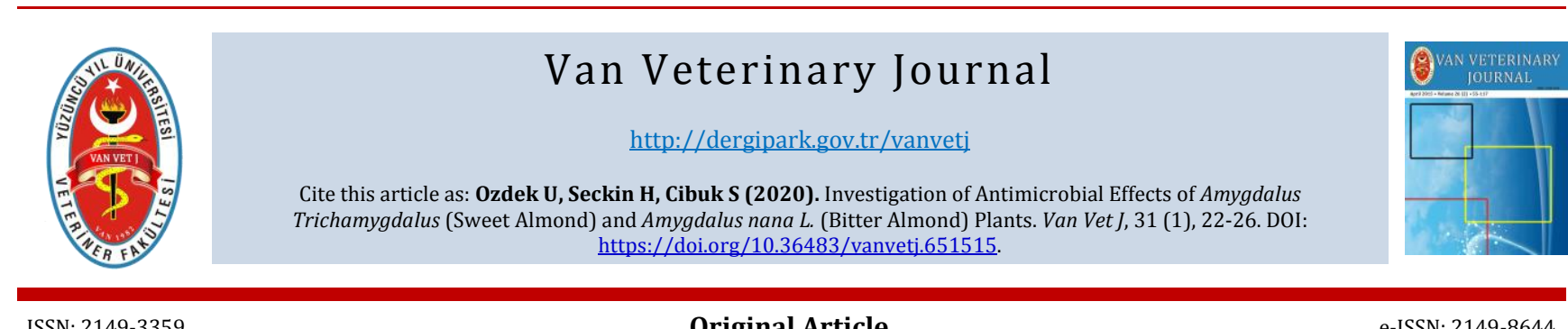

ISSN: 2149-3359

Original Article

e-ISSN: $2149-8644$

\title{
Investigation of Antimicrobial Effects of Amygdalus Trichamygdalus (Sweet Almond) and Amygdalus nana L. (Bitter Almond) Plants
}

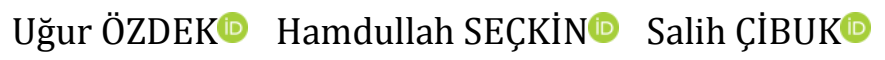 \\ Van Yuzuncu Yil University, Van Health Services Vocational School, Van, Turkey
}

Received: 27.11 .2019

Accepted: 17.01 .2020

\begin{abstract}
In this study, the antimicrobial effect of bitter almond (Amygdalus nana L.) and sweet almond (Amygdalus trichamygdalus) extract were investigated. The extracts of the sweet almond which plants collected from Diyarbakır Ergani district and the extracts of the bitter almond which plants collected from Van Tuşba district. The almonds dissolved in deionized water, alcohol, and ether. Fungus, gram positive and gram negative bacteria were used as pathogens in this study. The effects of the extracts on pathogens were determined by using the disk diffusion method. According to the zones that were formed by almond extract against bacteria; The highest inhibitory effect of the extract of Amygdalus nana L. (Bitter Almond) showed the highest inhibitory effect on Enterococcus faecalis and the extract of Amygdalus trichamygdalus (Sweet Almond) on Staphylococcus aureus and Escherichia coli.
\end{abstract}

Keywords: Amygdalus Nana L., Amygdalus Trichamygdalus, Antimicrobial Effect, Extraction

ÖZ

\section{Amygdalus Trichamygdalus (Tatlı Badem) ve Amygdalus nana L. (Acı Badem) Bitkilerinin Antimikrobiyal Etkisinin Araştırılması}

Yapılan çalıșmada acıbadem (Amygdalus nana L.) ve tatlı badem (Amygdalus trichamygdalus) ekstraktlarının antimikrobiyal etkisi araştırılmıştır. Diyarbakır Ergani ilçesinden toplanan tatlı badem ve Van Tuşba ilçesinden toplanan acı badem bitkilerinin ekstraktlarının deiyonize su, alkol ve eter içerisinde çözünmesi sağlanmıștır. Çalışmada patojen olarak, maya mantarı, gram pozitif ve gram negatif bazı bakteriler kullanılmıștır. Ekstraktların patojenler üzerine etkileri disk difüzyon metodu kullanılarak belirlenmiștir. Badem ekstraktlarının bakterilere karșı olușturduğu zonlar göz önüne alındığında Amygdalus nana L. (Acı badem) bitkisininden elde edilen ekstraktın gösterdiği en yüksek inhibitör etkinin Enterococcus faecalis'e karşı olduğu belirlenmiştir. Amygdalus trichamygdalus (Tatlı Badem) bitkisinden elde edilen ekstraktın gösterdiği en yüksek inhibitör etkinin Staphylococcus aureus ve Escherichia coli bakterilerine karşı olduğu görülmüştür.

Anahtar Kelimeler: Amygdalus Nana L., Amygdalus Trichamygdalus, Antimikrobiyal Etki, Ekstraksiyon

\section{GíRiş}

Birçok bitkinin yapısında bulunan fenol bileşikleri, organik asit ve yağların özellikle patojen mikroorganizmalara karşı inhibe edici etki gösterdiği bilim insanları tarafından belirlenmiştir. İnsanların doğal ürünlere yönelmesi sonucunda bitkisel ürünlerin yapısında bulunan antimikrobik etken maddeler gıda endüstrisinde önemli bir noktaya gelmiștir (Şengün ve Öztürk 2018).

Bitkilerde bulunan ve sekonder metabolit olarak adlandırılan bileșikler genellikle alkaloitler fenolik asitler ve türevleri, kuinonlar, saponinler, flavonoitler, taninler ve çeşitleri, kumarinler ve terpenoitler olarak bilinir (Şengün ve Yücel 2015). Günümüzde enfeksiyon hastalıklarının tedavisi için kullanılan etken maddelerin yaklaşık \%80'inin bitkisel odaklı olduğu düşünülmektedir (Keleş ve ark. 2001). Allium schoenoprasum L. (Sirmo) yapraklarından elde edilen etanol ekstraktının karaciğer koruyucu (Hepatoprotektif) etkisinin olduğunu bildirilmektedir (Koçak ve ark. 2019). Bitkilerin içerisindeki bileșenlerin farklı etkilerinden dolayı birçok alanda kullanılmaktadır (Meydan 2019).

Kullanılan maddelerin in vitro etkinliğini belirlemek amacıyla mikroorganizmalara karşı denenmesi için antimikrobiyal aktivite çalışmaları gerçekleştirilir. Bu çalışmaların kolay uygulanabiliyor olması ve düşük maliyet gerektirmesi nedeniyle antibiyotik duyarlılığının saptanmasında yaygın olarak kullanılmaktadır (Canlı 2016). Bilim dünyasında, antimikrobiyal maddelerin elde edilmesinde ilerleme kaydedilmesine karşın, Staphylococcus, Streptococcus, Candida albicans ve 
Pseudomonas gibi ilaçlara dirençli mikroorganizmaların varlığı sürmektedir (Mann 2012).

Gıda ve kozmetik endüstrisinde kullanılan lavanta (Lavandula stoechas), ada çayı (Salvia officinalis), papatya (Matricaria chamomilla) ve kekik (Thymus vulgaris), bitkilerinden elde edilen uçucu yağlar ve etken maddelerin, bazı bakteri ve mantarların metabolizmalarını olumsuz etkilediği tespit edilmiștir (İlkimen ve Gülbandılar 2018).

Badem gülgiller familyasında bulunan güzel çiçekli bir ağacın meyvesidir. Badem meyvesi sert ve kabukludur. Ülkemizde birçok bölgede kuruyemiş olarak tüketilmektedir. Badem çok fazla miktarda mineral ve vitamin içerir. Ayrıca pekçok hastalığa iyi geldiğinden çok eski zamanlardan beri kullanılmaktadır. Acı bademler ve tatlı bademler olmak üzere iki gruba ayrılır. Acı bademler siyanidrik asit içerdiği için zehirlidir ve yenilmesi sakıncalıdır. Genellikle badem yağı çıkarmak için kullanılır (Özsu 2003). Bitki ekstraktları ve uçucu yağlar; gıdaların muhafazası, farmasötik, alternatip tıp ve doğal tedavilerde kullanımı dahil olmak üzere pek çok uygulamanın temelini oluşturmaktadır (Dulger ve Gonuz 2004).

Tatlı bademlerde siyanidrik asit ya çok az bulunur veya hiç yoktur. Ülkemizde badem neredeyse her yerde tohum olarak ekilebilen veya yetiştirilebilen bir ağaç meyvesidir. Badem yağı hem cilt için hem de kabız çocuklar için kabızlığı giderici olarak çok eskiden beri kullanılmaktadır. Ayrıca acı bademin kalp ve damar hastalıklarına karșı koruyucu etkisinin olduğu bilinmektedir. Bu etkilerinin yanında balgam sökücü, dalak ve ciğerden çıkan damarları açma, cinsel isteği artırma, cilt enfeksiyonunun etkilerini azaltma, bronşlar ve boğaz ağrılarını giderme gibi pekçok faydası olduğu söylenmektedir (Özsu 2003). Bazı bilim insanları birçok tıbbi bitkiyi tanımlamış ve bu bitkilerin içerisindeki etken maddelerin çoğunun etkisi bilimsel olarak kanıtlanmıştır (Ertürk 2003). Antimikrobiyal ajanların etki mekanizmaları, mikroorganizmaların hedef bölgeleri ve bakterinin hücresel yapısıyla ilișkilidir (Karaman 2011).

Günümüzde kullanılan sentez yoluyla elde edilen ilaçların yan etkilerinin fazla olmasından dolayı ve organizmaların antimikrobiyal sentetik ilaçlara karșı direnç olușturmaları sebebiyle modern tıbbın hastalık tedavisinde yetersiz olduğu bazı noktaları ortaya çıarmaktadır. Bundan dolayı doğal bitkisel kaynakların ve bu maddeleri taşıyan bitkilerin önemi gün geçtikçe artmaktadır (Nakipoğlu 1992). Yapmıș olduğumuz bu çalıșmada, ülkemizde birçok sektörde kullanılmak amacıyla yetiștirilen acı ve tatlı bademin farklı patojen mikroorganizmalar üzerine etkilerini incelemeyi amaçladık.

\section{MATERYAL ve METOT}

\section{Materyal}

Çalıșmada kullanılan tatlı badem (Amygdalus trichamygdalus) Diyarbakır Ergani ilçesindeki grikahverengi gövdeli, sık dalcıklı ve yaklaşık 6-7 metre uzunluğundaki ağaçlardan alınmıștır. Acl badem (Amygdalus nana L.) ise Van Tuşba ilçesindeki çalı formu şeklinde büyüyen parlak kahverengi gövdeli bitkilerden toplanmıștır.

\section{Referans Mikroorganizmaları}

$\mathrm{Bu}$ çalışmada sırasıyla kullanılan mikroorganizmalar; Staphylococcus aureus ATTC 29213, Escherichia coli ATCC 25952, Bacillus cereus ATCC 10876, Bacillus subtilis ATCC 6633, Pseudomonas aeruginosa ATCC 27853, Enterococcus faecalis ATCC 29212, Candida albicans ATTC 90028 olmak üzere 7 farklı referans suş kullanıldı. Mikroorganizmalar Van Yüzüncü Yıl Üniversitesi Fen Fakültesi Moleküler Biyoloji ve Genetik Bölümü Laboratuvarından temin edildi.

\section{Badem Eksraktlarının Hazırlanması}

Ekstratlar, Ozdek ve ark. (2018)'nın kullandıkları yöntemde minimal değişiklikler yapılarak hazırlandı. Toplanan meyveler, güneş altında 4-5 gün ince bir şekilde serilip sıkça karıştırıldıktan sonra kuruması sağlandı. Kontrolü yapılan ve nem düzeyi istenilen düzeye gelen bademler muhafazaya alındı. Dış kabuktan ayırma işlemi yapıldıktan sonra iki gün günește bekletilerek kuruması sağlandı.

Kurutma işleminden sonra bademlerin kabukları kırılarak içleri çıkarıldı. Bademler serin, kuru, havalı ortamda bir süre depolanarak muhafaza edildi. Daha sonra bir ögütücü yardımıyla toz haline getirildi. Her materyalden $15 \mathrm{~g}$ tartılarak $150 \mathrm{ml}$ çözücü (deiyonize su, etanol ve eter) içerisinde 48 saat bekletildi. Elde edilen çözeltiler vakumlu rotary evaporatörden geçirilerek çözücülerin buharlaşması sağlandı.

\section{Antimikrobiyal Aktivitenin Belirlenmesi}

Test edilecek mikroorganizmaların Müller Hinton besiyeri içinde aktive edilmiş kültürleri kullanıldı. Disk difüzyon metodu ile ekstraktlar patojen mikroorganizmalar üzerinde denendi (Murray ve ark. 1995). Stoklardan alınan mikroorganizmalar Müller Hinton besiyeri içinde 48 saat 37 @ C'de inkübe edildi. $10^{-1}$ dilüsyonu yapılan canlı kültürden steril swaplar yardımıyla önceden hazırlanmıș olan katı Nutrient Agar besiyeri üzerine ekimleri yapıldı. Bir süre beklenerek agarın bakteri solüsyonunu emmesi sağlandı. Daha sonra ekstrakt emdirilmiș diskler steril pens yardımıyla besiyerinin üzerine düzenli bir şekilde ve hafifçe bastırılarak yerleștirildi.

Pozitif kontrol olarak, kullanılan referans suşlara karşı etki gösteren Neomycin antibiyotiği kullanıldı. Bu şekilde hazırlanan petriler inkübasyon için $37^{\circ}{ }^{\circ} C^{\prime}$ de 48 saat boyunca bekletildi. İnkübasyon süresi sonunda oluşan inhibisyon zon çapları ölçülerek antimikrobiyal aktivite tespiti yapıldı.

\section{BULGULAR}

Amygdalus nana $L$. ve Amygdalus trichamygdalus bitkilerinin meyvelerinden elde edilen ekstraktların antimikrobiyal etkisinin araştırıldığı çalışmada, mikroorganizmalara karşı oluşan inhibisyon zon çapı ölçümleri Tablo 1, 2, 3, 4'te verildi.

Buna göre Amygdalus nana L. (Acl badem) bitkisininden elde edilen ekstraktın gösterdiği en yüksek inhibitör etkinin Enterococcus faecalis bakterisine karşı olduğu görüldü. Bunun yanı sıra Staphylococcus aureus ve Bacillus subtilis bakterilerine de etki ettiği gözlendi. Amygdalus trichamygdalus (Tatlı Badem) bitkisininden elde edilen ekstraktın gösterdiği en yüksek inhibitör etkinin Staphylococcus aureus ve Escherichia coli bakterilerine karşı olduğu görüldü.

Ayrica Bacillus subtilis, Pseudomonas aeruginosa ve Enterococcus faecalis bakterilerine de etki ettiği gözlendi. Her iki ekstraktın da Bacillus cereus ve Candida albicans mikroorganizmalarına karşı inhibitör etkisinin olmadığı görüldü. 
Tablo 1. Amygdalus nana L.ve Amygdalus trichamygdalus ekstraktlarının Staphylococcus aureus ve Escherichia coli bakterileri üzerine etkileri ve inhibisyon zonları.

Table 1. Effects of Amygdalus nana L. and Amygdalus trichamygdalus extracts on Staphylococcus aureus and Escherichia coli bacteria and inhibition zones.

\begin{tabular}{|c|c|c|c|c|c|c|c|c|}
\hline \multicolumn{9}{|c|}{ Test Mikroorganizmaları ve İnhibisyon Zonları } \\
\hline \multirow[t]{2}{*}{ Ekstrakt } & \multicolumn{3}{|c|}{ Staphylococcus aureus } & \multicolumn{3}{|c|}{ Escherichia coli } & \multirow[b]{2}{*}{ Eter } & \multirow[b]{2}{*}{$\begin{array}{l}\text { Neomycin } \\
\text { (Antibiyotik) }\end{array}$} \\
\hline & $\mathrm{Su}$ & Etanol & Eter & $\begin{array}{l}\text { Neomycin } \\
\text { (Antibiyotik) }\end{array}$ & $\mathrm{Su}$ & Etanol & & \\
\hline $\begin{array}{l}\text { Amygdalus } \\
\text { nana L. }\end{array}$ & Yok & 9 & 7 & 22 & Yok & Yok & Yok & 17 \\
\hline $\begin{array}{l}\text { Amygdalus } \\
\text { trichamygdalus }\end{array}$ & 11 & 12 & 10 & 18 & 11 & 11 & 9 & 18 \\
\hline
\end{tabular}

Tablo 2. Amygdalus nana L.ve Amygdalus trichamygdalus ekstraktlarının Bacillus cereus ve Bacillus subtilis bakterileri üzerine etkileri ve inhibisyon zonları.

Table 2. Effects of Amygdalus nana L. and Amygdalus trichamygdalus extracts on Bacillus cereus and Bacillus subtilis bacteria and inhibition zones.

\begin{tabular}{|c|c|c|c|c|c|c|c|c|}
\hline \multicolumn{9}{|c|}{ Test Mikroorganizmaları ve İnhibisyon Zonları } \\
\hline \multirow[t]{2}{*}{ Ekstrakt } & \multicolumn{3}{|c|}{ Bacillus cereus } & \multicolumn{3}{|c|}{ Bacillus subtilis } & \multirow[b]{2}{*}{ Eter } & \multirow[b]{2}{*}{$\begin{array}{l}\text { Neomycin } \\
\text { (Antibiyotik) }\end{array}$} \\
\hline & $\mathrm{Su}$ & Etanol & Eter & $\begin{array}{l}\text { Neomycin } \\
\text { (Antibiyotik) }\end{array}$ & $\mathrm{Su}$ & Etanol & & \\
\hline $\begin{array}{l}\text { Amygdalus } \\
\text { nana L. }\end{array}$ & Yok & Yok & Yok & 24 & Yok & 8 & 9 & 32 \\
\hline $\begin{array}{l}\text { Amygdalus } \\
\text { trichamygdalus }\end{array}$ & Yok & Yok & Yok & 24 & 7 & 11 & 8 & 24 \\
\hline
\end{tabular}

Tablo 3. Amygdalus nana L.ve Amygdalus trichamygdalus ekstraktlarmın Pseudomonas aeruginosa ve Enterococcus faecalis bakterileri üzerine etkileri ve inhibisyon zonları.

Table 3. Effects of Amygdalus nana L. and Amygdalus trichamygdalus extracts on Pseudomonas aeruginosa and Enterococcus faecalis bacteria and inhibition zones.

\begin{tabular}{|c|c|c|c|c|c|c|c|c|}
\hline \multicolumn{9}{|c|}{ Test Mikroorganizmaları ve İnhibisyon Zonları } \\
\hline \multirow[t]{2}{*}{ Ekstrakt } & \multicolumn{3}{|c|}{ Pseudomonas aeruginosa } & \multicolumn{3}{|c|}{ Enterococcus faecalis } & \multirow[b]{2}{*}{ Eter } & \multirow[b]{2}{*}{$\begin{array}{l}\text { Neomycin } \\
\text { (Antibiyotik) }\end{array}$} \\
\hline & $\mathrm{Su}$ & Etanol & Eter & $\begin{array}{l}\text { Neomycin } \\
\text { (Antibiyotik) }\end{array}$ & $\mathrm{Su}$ & Etanol & & \\
\hline $\begin{array}{l}\text { Amygdalus nana } \\
\text { L. }\end{array}$ & Yok & Yok & Yok & 10 & 8 & 12 & 11 & 13 \\
\hline $\begin{array}{l}\text { Amygdalus } \\
\text { trichamygdalus }\end{array}$ & Yok & 7 & 8 & 8 & Yok & 9 & 8 & 15 \\
\hline
\end{tabular}

Tablo 4. Amygdalus nana L.ve Amygdalus trichamygdalus ekstraktlarının Candida albicans bakterisi üzerine etkileri ve inhibisyon zonları.

Table 4. Effects of Amygdalus nana L. and Amygdalus trichamygdalus extracts on Candida albicans bacteria and inhibition zones.

Test Mikroorganizmaları ve İnhibisyon Zonları

\begin{tabular}{lcccl}
\hline \multicolumn{1}{c}{ Ekstrakt } & \multicolumn{4}{c}{ Candida albicans } \\
\hline & Su & Etanol & Eter & $\begin{array}{l}\text { Neomycin } \\
\text { (Antibiyotik) }\end{array}$ \\
\hline $\begin{array}{l}\text { Amygdalus } \\
\text { nana L. }\end{array}$ & yok & yok & yok & 7 \\
$\begin{array}{l}\text { Amygdalus } \\
\text { trichamygdalus }\end{array}$ & yok & yok & yok & 6 \\
\hline
\end{tabular}




\section{TARTISMA ve SONUC}

İnsanların doğal ve sağlıklı gıdalara yönelmesi ile birlikte tıbbi ve aromatik bitkilerin değeri ve önemi her geçen gün daha çok artmaktadır. Bitkilerle yapılan çalışmalar önemli hale gelmiștir. Bitkilerden elde edilen etken maddelerden doğal ilaç üretimi sağlanabilmesinden dolayı bitkilere olan ilgi gün geçtikçe daha da artmaktadır (Baytop 1984). Son yıllarda antibiyotiklere direnç sağlayan bakterilerin ortaya çıkması ve doğal kaynaklı ilaçlarda görülmeyen ya da çok az görülen yan etkilerin sentetik ilaçlarda çok olması, bilim insanlarını doğal kaynaklı ilaçları araştırmaya yöneltmiştir (Dürger ve ark. 1999). Bitkilerden elde edilen etken maddelerin patojen mikroorganizmalara karșı göstermiș olduğu etkinin belirlenmesi, gittikçe artış gösteren antibiyotik direncinin önlenmesi noktasında çözüm olacaktır (Singh ve ark. 2011). Bitkilerin tedavi amaçlı kullanımı çok eski tarihlere dayanır. Geleneksel ilaç olarak kullanılan pek çok bitki bulunmaktadır (Parseh ve ark. 2012). Mikroorganizmaların antibiyotiklere direnç kazanmaları ve yeni patojen mikroorganizmaların ortaya çıkmasından dolayı günümüzde bilim insanları, tıbbi ve aromatik bitkilerin antimikrobiyal özelliklerini araștırmaya yönelmișlerdir (Naz ve ark. 2007). Öztürk ve Hamzaçebi (2019) yaptığı çalışmada, Ulva lactuca ekstraktlarının bazı gram pozitif bakterilere karşı yüksek etki gösterdiğini ve çözücü olarak etanol'ün kullanıldığı ekstraktın çok etkili olduğunu ve sonuç olarak Ulva lactuca'dan elde edilen ekstraktın gıda ve ilaç sektöründe koruyucu madde potansiyelinin olduğunu tespit etmiștir. Yapmış olduğumuz çalışmada kullanılan bitki ekstraktlarının patojenlere karşı oluşturduğu zonlar göz önüne alındığında özellikle farmasötik alanlarda kullanılabilecek etken madde içerme potansiyeli olduğu düșünülmektedir.

Sinop ilinde dört bitki ile hazırlanan (Jurinea kilae, Isatis arenaria, Verbascum degenii ve Pancratium maritimum) metanol ve etil alkol ekstraktlarının, bazı hastalardan izole edilen enfeksiyon sebebi mikroorganizmalar üzerine çok önemli antimikrobiyal faaliyet gösterdikleri tespit edilmiştir (Avşar ve ark. 2016). Tunç ve ark. (2013) Punica grantum L. (Nar) bitkisinin meyve kabuklarından elde ettikleri ekstraktları antibakteriyel olarak çalışmıștır. Çalışma sonucunda bitki ekstraktlarının en geniş inhibisyon zon çaplarını Staphylococcus aureus ve Staphylococcus epidermis bakterilerine karşı gösterdiğini tespit etmişlerdir. Pterigynandrum filiforme karayosunundan elde edilen ekstraktın bazı bakteri ve maya türüne karşı yapılan antimikrobiyal inceleme sonucunda gram pozitif ve gram negatif olan bazı bakteri türlerine etki ettiği bildirilmiștir (Yetgin ve ark. 2017). Bu çalışmada elde ettiğimiz sonuçlara bakıldığında maya mantarına karşı antifungal etkinin olmadı̆̆ı, buna karşın gram pozitif ve gram negatif bazı bakterilere karşı antibakteriyel etkinin görüldüğü belirlendi.

Zonguldak'ta bazı aktarlardan alınan Portakal, Limon, Kavun, Nar Çekirdeği Yağı ve Ahududu bitkilerinden elde edilen özütlerin antimikrobiyal aktivitesi incelenmiş ve mikroorganizmalara karșı etkisinin olduğu belirlenmiştir (Koçer ve Sugeçti 2015). Eliuz (2018) yaptığı çalışmada zeytinyağı ve mahlep yağı içeriklerini Escherichia coli ve Bacillus subtilis mikroorganizmaları üzerine etkilerini inceleyerek etnobotanik açıdan önemli sonuçlar elde etmiştir.

Çalışmamızda Amygdalus nana L. bitkisinin meyvelerinden elde edilen ekstraktın idrar, kan, yaralar ve balgam olmak üzere bir çok yerde bulunan patojen Enterococcus faecalis
(Dinç ve ark. 2009) bakterisine karşı güçlü antibakteriyel etki gösterdiği gözlendi. Amygdalus trichamygdalus meyvelerinden elde edilen ekstraktın ise Staphylococcus aureus ve Escherichia coli bakterilerine karşı güçlü antibakteriyel etki gösterdiği gözlendi.

Doğada birçok bitki, bakteri ve mantarın mikrobiyal ajanlara karşı etki gösterdiği bilinmektedir. Bu çalışmada badem meyvesi ekstraktlarının bazı patojen bakterilere karşı etkileri invitro olarak çalışıldı. Önemli bulgular elde ettiğimiz bu çalışmamızda bitki ekstraktlarının içerik analizleri sonucunda antimikrobiyal etkiyi meydana getiren faktörlerin tespit edilmesi ile başta sağlık sektörü olmak üzere birçok alanda bilim dünyasına katkı sağlayacağı kanaatindeyiz.

\section{KAYNAKLAR}

Avşar C, Keskin H, Berber İ (2016). Hastane İnfeksiyonlarından İzole Edilen Mikroorganizmalara Karșı Bazı Bitki Ekstraktlarının Antimikrobiyal Aktivitesi. Int J Pure Appl Sc, 2(1), 22-29.

Baytop T (1984). Türkiye'de Bitkiler ile Tedavi, İstanbul Üniv. Yay. No. 3637, Eczacılık Fakültesi, No. 40, İstanbul, 240-376.

Canlı K, Yetgin A, Akata I, Altuner EM (2016). In vitro Antimicrobial Activity of Angelica sylvestris Roots. Int J Biol Sci, 1(1), 1-7.

Dinç BM, Arca EA, Yağcı S, Karabiber N (2009). In-vitro Antibotic Susceptibility of Enterococcus faecalis and Enterococcus faecium Strains Isolated from Various Clinical Samples. Turk Hij Den Biyol Dergisi, 66(3), 117-121.

Dulger B, Gonuz A (2004). Antimicrobial Activity of Certain Plants used in Turkish Traditional Medicine. Asian J Plant Sci, 3 (1), 104-107.

Dürger B, Ceyhan M, Alitsaous M, Uğurlu E (1999). Artemisia absinthium L. (Pelin)'un Antimikrobiyal Aktivitesi. J Of Biology, 23, 377-384.

Eliuz EAE (2018). Zeytin Yağı Mahlab Yağı Kombinasyonlarının E. coli ve $B$. subtilis'e Karșı Değerlendirilmesi 3. International Mediterranean Science and Engineering Congress (IMSEC) October 24-26, Adana/Turkey.

Ertürk 0̈, Demirbağ Z (2003). Scorzonare mollis Bieb (Compositae) Bitkisinin Antimikrobiyal Aktivitesi. Ekoloji, 12(47), 27-31.

İlkimen H, Gülbandılar A (2018). Lavanta, Ada Çayı, Kekik ve Papatya Ekstrelerinin Antimikrobiyal Etkilerinin Araştırılması. Türk Mikrobiyol Cem Derg, 48(4), 241-246.

Karaman P (2011). Bazı aromatik bitki türlerinin antimikrobiyal, antioksidan ve DNA koruyucu aktivitelerinin belirlenmesi. Fen Bilimleri Enstitüsü, Moleküler Biyoloji ve Genetik Anabilim Dalı, Yüksek Lisans Tezi, Sivas Cumhuriyet Üniversitesi.

Keleș O, Ak S, Bakırel T, Alpınar K (2001). Türkiye'de yetișen baz bitkilerin antibakteriyel etkisinin incelenmesi. Turk J Vet Anim Sci, 25, 559-565.

Koçak Y, Oto G, Yücel UM, Yașar S, Arıhan 0 (2019). Karbon tetraklorür ile oluşturulan doku hasarında Allium schoenoprasum L. uygulamasının karaciğer ve böbrek dokusunda total antioksidan ve total oksidan düzeylerine etkisi. Van Sag Bil Derg, 12(3), 1-10.

Koçer F, Sugeçti S (2015). Ticari Öneme Sahip Doğal Özütlerin Klinik Patojen Mikroorganizmalara Karşı Antimikrobiyal Aktivitesi. Anadolu Doğa Bilimleri Dergisi, 6 (Özel Sayı 2), 28-34.

Mann A (2012). Evaluation of antimicrobial activity of Anogeissus leiocarpus and Terminalia avicennioides against infectious diseases prevalent in hospital environments in Nigeria. J Microbiol Res, 2(1), 610

Meydan İ (2019). Badem (Amygdalus Trichamygdalus) Meyvesinin Etano Ekstraktı ve Yağının Gs-Ms ile Karakterizasyonu. Inf Tech and Ap Sci, 14 (2), 241-250.

Murray PR, Baron EJ, Pfaller MA, Tenover FC, Yolken RH (1995). Manual of Clinical Microbiology, Washington: ASM.

Nakipoğlu M, Otan H (1992). Tıbbi Bitkilerin Flavonitleri. Anadolu J of AARI, 4(1), 70-93.

Naz S, Ahmad S, Rasool SA, Siddiqi R, Sayeed SA (2007). In vitro Antibacterial Activity of the Extracts Derived from Terminalia catappa. Res J Microbiol, 2 (2), 180-184.

Özdek U, Başbuğan Y, Yıldırım S, Boğa M, Fırat M, Değer Y (2018). Activity, acute and sub-acute toxicity and safety assesment of the hydroalcholic root extract of Diplotaenia turcica. Indian J Anim Res, 52(12), 1688-1694.

Özsu B (2003). Badem sektörü. h t t p s : / / w w w . y u m p u . c o m / t r / d ocument/read/23585247/badem-etudu-raporu $-2003-$ ito. 
Öztürk F, Hamzaçebi S (2019). Farklı Çözgenlerle Elde Edilmiş Ulva lactuca Ekstraktlarının Antibakteriyal Aktivitesi. Act Aqua Tr, 15(3), 272-279.

Parseh H, Hassanpour S, Emam-Djome Z, Lavasani AS (2012) Antimicrobial Properties of Pomegranate (Punica granatum L.) as a Tannin Rich Fruit: a Review, The 1th International and The 4th National Congress on Recycling of Organic Waste in Agriculture, Iran.

Singh B, Dutt N, Kumar D, Singh S, Mahajan R (2011). Taxonomy, ethnobotany and antimicrobial activity of Croton bonplandianum Euphorbia hirta and Phyllanthus fraternus. J Adv Develop Res, 2(1), 219.

Șengün İY, Öztürk B (2018). Anadolu Üniv. Bil.Tek. Der. C - Yașam Bil. ve Biyotek, 7 (2).
Şengün İY, Yücel E (2015). Antimicrobial properties of wild fruits. Bio Di Con, 8(1), 69-77.

Tunç K, Konca T, Hoş A (2013). Punica granatum Linn. (nar) bitkisinin antibakteriyel etkisinin araştırılması, SAÜ. Fen Bil. Der, 17(2), 167-172.

Yetgin A, Şenturan M, Benek A, Efe E,Canlı K (2017). Pterigynandrum filiforme Hedw. Türünün Antimikrobiyal Aktivitesinin Belirlenmesi. Anatolian Bryo, 3(1), 43-47. 